patients. Exactly which is the best treatment regimen is a separate issue.

Department of Surgery,

Rayne Institute,

University College London,

London WC1E 6JJ

1 Schröder FH. Prostatic cancer: to screen or not to screen? BMJ 1993;306:407-8. (13 February.)

Whitmore WF Jr. Natural history of low-stage prostatic cancer and the impact of early detection. Urol Clin N Am 1990;17:689.

3 George NJR. Natural history of localised prostatic cancer managed by conservative therapy alone. Lancet 1988;iii:494-7.

$4 \mathrm{McNeal}$ JE, Bostwick DG, Kindrachuk RA, Redwine EA, Freiha FS, Stamey TA. Patterns of progression in prostate cancer. Lancet 1986;:60-3.

5 Walsh PC. Why make an early diagnosis of prostate cancer? $\mathcal{f}$ Urol 1992;147:853-4.

6 Möller Jensen O, Esteve J, Renard H. Cancer in the European Community and its member states. Eur f Cancer 1990;26: 1167-256.

EDITOR,-Fritz H Schröder rightly emphasises that it is not known whether treatment of early prostatic cancer is beneficial or whether screening for the disease offers any advantage.' This debate will never be resolved unless it can firmly be established whether searching for early prostatic cancer on a community basis is worthwhile in clinical, resource, and social terms.

In Gwent we have embarked on a major study to do this and will be offering a prostate health check to over 10000 men aged between 55 and 70 in a study that is associated with the European programme concerned with early prostatic cancer. We aim to complete the groundwork within 12 months but hope that concurrently British urologists will agree to work together in a randomised study of treatment for prostatic cancer confined to the organ. Radical prostatectomy is likely to be one treatment arm. We wonder, however, whether a surveillance arm would be acceptable to many ethics committees and patients now that informed consent is mandatory.

J S A GREEN

W B PEELING

Department of Urology,

Royal Gwent Hospital,
Newport, Gwent NP9 2UB

1 Schröder FH. Prostatic cancer: to screen or not to screen? BMF 1993;306:407-8. (13 February.)

EDITOR,-Though we agree with Fritz H Schröder that some of the intriguing scientific questions about the natural course of prostatic cancer could be answered in a randomised controlled trial of screening,' we are concerned that the possible adverse effects of screening may be arguments against such an exercise.

Schröder estimates that the detection rate is $2.5 \%$, which is 15 times the present incidence of 1.4 new cases/ 1000 men aged 60 to 74 in England and Wales. Such a high ratio of prevalence to incidence suggests either a long lead time, which is not typical of the invasive cancers that are the intended target of the screening programme, or a large element of overdiagnosis of slowly progressive disease, or both

We estimate that 150000 men aged 60 to 74 would be required in an evaluative trial for it to have an $80 \%$ chance of showing a $20 \%$ reduction in mortality over the ensuing 10 years, significant at the $5 \%$ level. Given the incidence and case fatality in British men aged 60 to 74 at entry, such a $20 \%$ reduction in 10 year mortality would amount to 81 fewer deaths in the 75000 men offered screening. On the assumption that $60 \%$ would attend for screening, 1125 of those might be diagnosed as having prostatic cancer at the first screen. All these men (and presumably others with cancers detected at subsequent screening rounds) would be exposed to the risks of radical prostatectomy, which may cause impotency in up to $42 \%^{2}$ and urethrovesical stricture in $7 \% .^{3}$ Radiation therapy may cause short term effects such as sickness and long term effects such as urinary and intestinal problems and fibrosis of soft tissue. ${ }^{4}$ The adverse consequences to the health of men in their seventh, eighth, and ninth decades could thus be considerable and might well counterbalance the small benefit of screening in terms of reduced deaths.

Perhaps it would be wiser to concentrate research on the development of non-invasive biological markers to distinguish rapidly progressive from slowly progressive tumours as well as on the development of less invasive (for example, endocrine) treatment. With such tools for diagnosis and treatment, screening for prostatic cancer would be much more feasible.

\section{S MOSS RELLMAN} JMELIA J CHAMBERIAIN

Institute of Cancer Research: Royal Cancer Hospital,

Cancer Screening Evaluation Unit,

Sutton, Surrey SM2 $5 \mathrm{NC}$

1 Schröder FH. Prostate cancer: to screen or not to screen? $B M$ 1993;306:407-8. (13 February.)

2 Catalona WJ, Bigg SW. Nerve-sparing radical prostatectomy: evaluation of results after 250 patients. F Urol 1990;143: 538-44.

3 Walsh PC. Radical retropubic prostatectomy. In: Walsh PC Gites B, Perlmutter A, Stamey TA, eds. Campbell's urology. Vol 3. Philadelphia: Saunders, 1986:2772-5.

4 Shipley WU, Prout GR Jr, Coachman NM, McManus PL, Healey EA, Althausen AF, et al. Radiation therapy for Healey EA, Althausen AF, et al. Radiation therapy for
localized prostate carcinoma: experience at the Massachusetts localized prostate carcinoma: experience at the Massachusetts

Prorok PC, Byar DP, Smart CR, Baker SG, Connor RJ. Evaluation of screening for prostate, lung and colorectal Evaluation of screening for prostate, lung and colorectal
cancers: the PLC trial. In: Miller AB, Chamberlain J, Day NE, Hakama M, Prorok PC, eds. Cancer screening. Cambridge: Cambridge University Press, 1991:300-20.

AUTHOR'S REPLY,-Kate Lawrence and colleagues criticise the concluding statement of the US National Cancer Institute's consensus conference (reference 9 in my editorial) that effective treatment of prostatic cancer is available. I was careful to review the effectiveness of treatment and to state that no evidence of effectiveness of radiotherapy and radical prostatectomy is available from prospective randomised comparative studies. The effectiveness of a procedure can, however, also be defined as its ability to eradicate tumour locally. In this sense, with the usual limitations of any procedure applied to patients with cancer, the two available techniques are effective. Local eradication of prostatic cancer probably occurs more commonly with radical prostatectomy than with radiotherapy.

Several times Lawrence and colleagues accentuate the damaging effect of treatment on patients with cancer of the prostate. This is where I disagree. Radical surgery for prostatic cancer has become acceptable so far as long term functional results are concerned: continence can be maintained or restored in virtually all patients, and potency is maintained in $50-70 \%$ of those who are potent preoperatively. I made clear in the editorial that no randomised comparative trial is available and that there is an urgent need for such information. Several attempts to carry out such studies, however, have shown the great logistic difficulties entailed, which may prevent such a study in the future. A Scandinavian study uses a randomisation scheme which will probably prevent the group from obtaining a scientifically valuable result. To my mind the only possibility of solving this problem lies in a large European prospective randomised screening study comparing screening with no screening and using mortality from prostatic cancer as its major end point. Pilot studies for such a European protocol are currently being conducted.

FRITZ H SCHRÖDER

Department of Urology

Erasmus University,

3000 DR Rotterdam,

Netherlands

\section{Dangers of long waiting times}

EDIToR,-It is a fact of life that any specialist outpatient clinic will have a waiting list. Priorities regarding the degree of urgency of an appointment must be decided on the basis of the information received in the referral letter.

It is salutary that in their report on the dangers of long waiting times for outpatient appointments at a urology clinic $\mathrm{K}$ German and colleagues say that five of the seven cases of prostatic cancer were detected on rectal examination and one by a raised serum prostate specific antigen concentration. Unless general practitioners can be persuaded that a digital rectal examination is not a physical assault and that measurement of serum prostate specific antigen concentration is a sensitive screening test for prostatic cancer, no progress will be made in detecting prostatic cancer. Both of these investigations should be mandatory in patients presenting with symptoms of bladder outflow obstruction, and if either is abnormal some priority can be afforded to the referral letter, particularly if the patient is aged under 65 .

The authors do not state whether they actually treated the patients found to have prostatic cancer. The patients' symptoms of bladder outflow obstruction may well have been due to benign prostatic hypertrophy and the coexistent prostatic cancer may have been an incidental finding. For patients in the usual age group who present with symptomatic outflow obstruction and have "incidental" well differentiated prostatic cancer confined to the gland, most urologists in Britain would perform a transurethral resecton to relieve the symptoms but adopt a policy of watchful waiting regarding the cancer. In other words, the delay in initial diagnosis of a few months may not matter that much to the urological management of most such patients in Britain.

Department of Urology,

Bouthmead Hospit

German K, Nuwahid F, Matthews P, Stephenson T. Dangers of long waiting times for outpatient appointments at a urolog long waiting times for outpatient appoint
clinic. BMF 1993;306:429. (13 February.)

\section{Reducing waiting lists requires more staff}

EDITOR,-K German and colleagues' paper and Catherine Pope's editorial emphasise the current attention directed at reducing waiting lists in the NHS. ${ }^{2}$ Much of the debate has related to reducing waiting times for surgery rather than for outpatient appointments.

As in urology,' in neurology waiting times for outpatient appointments are too long despite the unacceptably large numbers of patients seen in outpatient clinics. Similar anxieties exist about the morbidity and mortality of patients who cannot be seen within a satisfactory time. This picture is not specific to neurology services in this regional centre. It is replicated at other centres and units in district general hospitals providing neurological services throughout Britain. Waiting times in this centre exceed five months despite full clinics and extra, urgent cases being seen outside normal times set aside for outpatient clinics.

The medical problem is directly related to the inadequacy of available resources. The necessary solution lies in additional consultant appointments and also additional staff in training grades. These problems need to be addressed before waiting lists can be responsibly reduced. A critical level of professional staff is required to provide adequately for the clinical needs of patients who are referred, irrespective of additional needs to provide excellence in postgraduate clinical training and research. 